\title{
"Cultural Re-Entry": Pedagogical application of a simple descriptive analysis of the dynamics of cross-cultural encounter for students of International Commerce
}

\section{Suzette Brace-Le Bigot}

\section{(2) OpenEdition}

\section{Journals}

Electronic version

URL: http://journals.openedition.org/asp/4093

DOI: $10.4000 /$ asp.4093

ISSN: 2108-6354

\section{Publisher}

Groupe d'étude et de recherche en anglais de spécialité

\section{Printed version}

Date of publication: 1 December 1994

Number of pages: $217-222$

ISSN: 1246-8185

\section{Electronic reference}

Suzette Brace-Le Bigot, « "Cultural Re-Entry": Pedagogical application of a simple descriptive analysis of the dynamics of cross-cultural encounter for students of International Commerce », ASp [Online], 5-6 | 1994, Online since 19 December 2013, connection on 19 April 2019. URL : http:// journals.openedition.org/asp/4093 ; DOI : 10.4000/asp.4093

This text was automatically generated on 19 April 2019.

Tous droits réservés 


\title{
"Cultural Re-Entry": Pedagogical application of a simple descriptive analysis of the dynamics of cross- cultural encounter for students of International Commerce
}

\author{
Suzette Brace-Le Bigot
}

1 Students pursuing a DUTA in International Commerce at the Institut Universitaire de Technologie of the University of Paris 5 participate in a "cultural re-entry" program following three months of professional internship in a foreign country. The first few English classes are devoted to the presentation of a simple descriptive analysis of the dynamics of attraction and refusal involved in cross-cultural encounter and to group "consciousness-raising" exercises designed to encourage students to share their recent experiences abroad and to reflect on the influence of maternal culture on perceptions of the unfamiliar.

2 During these sessions students are to identify what areas of activity did in fact lead to discomfort or conflict when interacting with members of another culture. It is quite important that they attempt to situate, understand, and assume their reactions to cultural differences as they are scheduled to leave for a second professional internship in a foreign company after one semester of specialized university instruction.

3 Although this program is specifically designed for the DUTA candidates returning to the University environment described above, the principles and exercises involved would also be appropriate for students preparing to leave for another country as well as for those engaged in textual analysis of documents created for members of another national group. Educators admit that when examining such texts it is not sufficient to identify cultural "facts". The significance of these "facts" in the culture in which they originate must also be understood. Greater comprehension of the role of culture -both maternal and target-greatly enhances documentary studies as well as travel experiences. 


\section{Cross-cultural training programs}

4 and the "unfamiliar" (the target culture).

\section{Programs concerning "the perceived": cognitive input about the target culture}

Presently, most training programs in cultural awareness focus essentially on the second element mentioned above, the "perceived" rather than the "perceiver". Students are provided with valuable cognitive input concerning appropriate behavior in another culture: eating, dressing, greeting/leave-taking, religious practices, taboo subjects, punctuality... One cannot deny the value of such information:

- Anxiety is reduced. When we feel that we know what to expect in an unfamiliar environment, we are far less apprehensive about embarking upon a cross-cultural adventure.

- Errors can be avoided. When we possess information about what kind of behavior is and is not deemed acceptable by our foreign hosts, we are far better outfitted to engage in satisfying exchange without offending our new partners.

- Active participation of the learner is encouraged. Guidelines are motivating: when we believe that we know what behavior is correct, we are far more willing to take part in activities in a foreign environment and are less inclined to sit on the sidelines as observers.

However, one must not forget the obvious limitations of programs focusing exclusively on the target culture.

- Practices change

- Generalizations do not apply to all situations.

- Limited information may encourage unfounded confidence (a "placebo effect"). Unfortunately, it can be quite satisfying - and misleading at the same time - to possess superficial knowledge about the target culture. "I have read extensively about that culture. I know what to expect." While such an attitude may comfort the learner, it may very well discourage - or at least inhibit - careful observation of the unfamiliar environment.

- Temporary adaptation to immediate needs ("survival tactics") may remain the sole objective of such a program.

7 Therefore, if cross-cultural investigation is to be pursued at a truly enriching level involving a long-range perspective, training should focus not only on the perceived, but also on the perceiver and on the role of maternal culture in the discovery process.

\section{Programs Concerning the "perceiver": seven phases of discovery}

In the cultural re-entry program, DUTA students examine a simple descriptive analysis of seven of the possible attitudes that might be manifested by a subject confronted with cultural differences. ${ }^{1}$ For purposes of identification, these seven attitudes, or behavior patterns, are called "phases". The initial phase applies to subjects with extremely limited experience with otherness. Five other phases of discovery lead to a final, culminating one describing the behavior of the individual capable of making responsible choices when solicited simultaneously by values acquired in the maternal culture and by alternatives proposed by another culture.

9 Care is taken not to present these phases in terms of a linear progression from "inferior" to "superior". Each of the behavior patterns evoked is appropriate in a certain set of 
circumstances. (A parallel could be drawn with tenses in grammar: the future tense is not superior to the present tense nor inferior to the imperfect - each one is suitable in a specific context.)

10 What are these seven phases and how are they presented and pedagogically exploited in the cultural re-entry program? Let us examine the following list in table 1.

Table 1: Seven phases of cross-cultural discovery

\begin{tabular}{|l|l|}
\hline native perspective & security, guidance, certitude \\
\hline awareness of non-universal perspective & alternatives, other-ness \\
\hline differentiation & protection, retreat to the familiar \\
\hline exploration & investigation, vacillation \\
\hline confrontation & conflict, refusal \\
\hline enlargement of perspective & situating significance of "facts", facts = tools \\
\hline disengagement & freedom to choose \\
\hline
\end{tabular}

\section{Descriptions of the seven phases}

\section{Native perspective}

When identical behavior patterns are shared by nearly everyone in an environment, the members of the dominant group tend to be unaware of the fact that the inherited, unanalyzed values that orient daily lives (right/wrong, beautiful/ugly) are not universally shared. Much of a culture is unconscious. The values and ways of thinking learned in a native culture seem "natural", "normal", "innate" to subjects with a native perspective. The centrisms and phobias which determine our sense of identity, dictate our behavior, orient our perspectives, and influence our evaluations of familiar and unfamiliar phenomena provide us with precious security and guidance. For this reason, we tend to perceive our culture as comforting rather than limiting. Unless we make a conscious effort to probe what conditions our attitudes, we consider what we have always done and seen done - and perhaps have never really thought about - as normal.

\section{Awareness of non-universal perspective}

Awareness of others begins with the acknowledgement that the shared values which dictate behavior are not absolutes, but are, in reality, tools or patterns of behavior constructed to respond to the needs arising from given living situations within a culture. Other tools, or solutions, are equally possible. Members of other cultures have their own perceptions, representations, and appreciations which seem equally natural and valid to them.

\section{Differentiation}

13 The discovery that others do not react as we do casts doubt on our habitual, accepted behavior and leads to questioning that which has always seemed comfortable. The 
ensuing destabilization can cause upset or anxiety, both of which trigger defense mechanisms such as diminishing the other ("Americans have no history.") or establishing a comfortable distance between one's own familiar territory and that which is perceived as menacing ("France is a good place to be. People know how to appreciate the good things in life. There is really no reason to go any place else.") At this initial stage of contact with the unfamiliar, the individual is inclined to seek protection by retreating to the intimacy or solidarity of his/her own group.

\section{Exploration}

The uncertainty provoked by an encounter with outsiders is unsettling, but it may serve as a catalyst for questioning one's values and habits. During the period of exploration the individual is alternately solicited by the forces of assimilation and differentiation: he/she may feel the need for the security of the maternal group and at the same time the attraction of the unknown. The degree of attraction or repulsion provoked by the unfamiliar is largely determined by the degree of threat the outside phenomenon represents to the observer/learner. Only the individual encountering the unfamiliar can measure the amount of innovation and audacity which is tolerable for him/her at a given moment. Even if refusal of a proposed cultural alternative may well be legitimate in that it constitutes what seems to be the only reaction possible for an individual at a given time, it is significant that the learner has been willing to give due consideration to what was previously an unexamined cultural practice.

Therefore, to successfully deal with the threat of the unfamiliar, it is essential that each individual develop a dynamic conception of uncertainty, a conception which allows him/ her to openly admit fears, resistance, reservations - even anguish - as well as to acknowledge other defensive attitudes to which he/she has recourse when experiencing discomfort due to the threat of that which is different. Only when the learner identifies and admits his/her insecurity and protective devices can the complexity of other cultures be examined with ease and involvement.

It is my experience that most cross-cultural training programs deal only with these first four phases of discovery of the unfamiliar. The learner becomes aware of the fact that native culture influences perception, that members of other cultures do not necessarily share the same visions that he/she does, that all cultures construct mechanisms to protect themselves from the unfamiliar, and that what is comfortable for one group is not necessarily so for another.

Limiting horizons in this way is most regrettable, for if the discovery of another culture is to become an undertaking which is more ambitious than adaptation to the immediate needs of a given moment, the importance of cultural differences must not be minimized. More specifically, if cross-cultural investigation is to be pursued on a personally enriching level with long-range implications, educators must muster the courage necessary to address the irreconcilable conflicts which may exist between between the maternal and target cultures.

The construction of individual identity depends in large part upon the ability to distinguish oneself from others. (There is no "we" without "they".) It is naïve and unrealistic to pretend that "we are all brothers and sisters under the skin." Even if there is some narcissistic satisfaction to observing that others "seem just like us", it is abusive to over-simplify the content of cross-cultural investigation by dwelling exclusively upon those aspects of another culture which present no source of conflict to us. 


\section{Confrontation}

19 Like most discovery processes, the challenge of cross-cultural learning can involve disappointment, risk, frustration, and bewilderment as well as reward. If learners are to be authentically committed to in-depth pursuit in this domain, conflicts between cultural practices will inevitably be perceived. It is preferable to deal openly with such difficulties, for to avoid confrontation at all costs may result in reducing intercultural discovery to mere satisfaction with "information for the sake of information". ("That's just how it is. There's nothing we can do about it. Live and let live. I'm OK, you're OK.") Such an attitude suggests that there can be a very fine line between tolerance and indifference.

On the other hand, it is probable that the learner who is deeply involved will inevitably come to a point where some practices of the target culture seem unacceptable to him/ her. In this case it is essential to respect the right of refusal of the individual. We are not alike; we must learn to live with this fact. Even if this phase of discovery often involves uncomfortable, affectively charged exchanges between students, this step acknowledging and addressing true, irreconcilable differences between cultural practices - is necessary if we are to move toward mature, authentic exchanges with individuals from an environment different from ours.

\section{Enlargement of perspective}

This phase of discovery is more comfortable, more intellectual, safer than the preceding one. Admitting that other frames of reference, other habits, other forms of reasoning are just as acceptable as those with which we are familiar is a first step toward assuming the perspective of another in assessing cultural facts. During this phase the learner no longer applies the values learned in the maternal culture to judge the behavior of another group. Rather, he/she attempts to identify the structured system of values which condition an unfamiliar cultural practice and to seize the significance of the act in question to a member of the foreign culture in which the act originates. In other words, this phase implies interpreting cultural practices as tools or solutions to everyday problems.

\section{Disengagement}

Investing cross-cultural inquiry with a personal commitment on the part of the learner in no way implies denial of one's own culture. It simply means being able to disengage oneself from a number of attitudes which have previously remained unquestioned in order to be free to examine (and perhaps adopt) alternatives. Disengagement involves a willingness to take the risk of exposing to questioning that which has been a source of protection, comfort, and security. It also involves identifying and accepting defense mechanisms (such as stereotypes) as natural, necessary reactions to confronting the unfamiliar. They are not social aberrations or pathologies, but, rather, "normal" means of coping with complexity, contradiction and uncertainty.

An individual attains disengagement through skillfully combining opportunities for contact with otherness with a conscious method of analysis of cultural differences. In this final phase of discovery a learner becomes free to choose responsibly what cultural practices (those acquired in the maternal culture or alternatives proposed by the target culture) seem the most appropriate or satisfying for him/herself. 


\section{Pedagogical exploitation of the analysis in the cultural re-entry program}

The scope of this paper does not allow for a thorough presentation of the series of activities which normally accompany the presentation of these seven phases of crosscultural discovery to DUTA students. Only an objective and an example of a corresponding activity will be presented for each phase.

\section{Native perspective}

Objective: to highlight dominant values rarely questioned in the maternal culture of the learners.

Exercise: Examine the following list of values. Which ones are important to the majority of the French? (justice, originality, charm, creativity, tolerance, scientific inquiry, cleanliness, physical fitness, discretion...).

\section{Awareness of non-universal perspective}

Objective: to examine alternatives to practices that are prevalent in the maternal culture which have been widely adopted by other cultures.

Exercise: Can you name manifestations of a value which is the opposite of one frequently associated with the French? (ex-haute cuisine, polished language, political tolerance...).

\section{Differentiation and exploration}

Objective: to propose situations which require the learner to choose between retreat to familiar territory, adventuring into the unknown, testing the unfamiliar with reserve and caution, or defensive behavior.

Exercise: Choose between three alternatives in response to the following situation:

-You fall ill in a foreign country. You (a) come right home to a French hospital, (b) go to a European hospital in a large city, (c) accept local health care (even if it involves healing practices and medicines not authorized in your own culture)

-You are sent with your family to work in a developing country for three years. Would you send your children to (a) a native school, (b) boarding school in France, (c) a French school in the capital of the country?

\section{Confrontation}

Objective: to identify true, irreconcilable differences which lead to inevitable conflicts between members of the maternal and target cultures.

Exercise: Consider the following practices which exist in some cultures, but which encounter resistance in France. Which ones could conceivably become prevalent practices in France? (arranged marriage, alcohol outlawed, legalized drugs, nudity on beaches, polygamy, make-up for men ...).

Enlargement of perspective

Objective: to demonstrate the social utility or cultural logic of foreign practices, to highlight that what works for one culture does not necessarily work for another.

Exercise: Identify the social utility of the following practices: legalized prostitution, celibacy of the clergy, excluding women from military combat, dress which conceals most of a woman's appearance... 


\section{Disengagement}

Objectives: (essentially overall objectives, as this could be considered the culminating phase of the process of cross-cultural discovery) to examine other cultures with a conscious method of analysis, to view cross-cultural experience as an additive process which does not involve denial of the maternal culture, to lessen anxiety when confronted with difference, to encourage at least moderate risk-taking in another culture, to respect the individual's right to refuse a cultural practice, to invest cultural learning with a longrange perspective.

Exercise: Examine results of questionnaires so that each individual identifies those areas (hygiene, medical care, hierarchy, sexuality, food, family, religion, education, security...)

39 - in which the learner is most/least comfortable in the maternal culture

- in which the learner is most likely to be attracted to alternatives proposed by (an)other culture(s)

- in which conflict or refusal is likely to arise when confronted with the unfamiliar

Navigating through these phases of cross-cultural awareness is a fascinating adventure. Let us hope that by examining with our students some of the normal reactions to the unfamiliar, cultural differences will no longer be perceived of as obstacles but rather as opportunities.

\section{NOTES}

1. See table 1 below.

\section{ABSTRACTS}

This paper describes a "cultural re-entry" program designed for students returning to the university environment after a professional internship in a foreign country. Unlike most crosscultural training programs which focus essentially on "the perceived" and provide cognitive input concerning the target culture, the re-entry program examines "the perceiver" and seven possible reactions to the unfamiliar manifested by the learner/observer. The seven "phases" of discovery analyzed range from native perspective (extremely limited experience with "otherness") to "disengagement" the capacity to make responsible choices when solicited simultaneously by values "acquired" in the maternal environment and alternatives "proposed" by another culture. To conclude, a pedagogical exploitation of the analysis, or a series of group "consciousness-raising" exercises, is proposed. 
Cette intervention a pour objet un programme de « dépressurisation culturelle » créé pour des étudiants de retour dans un milieu universitaire après un stage d'ordre professionnel dans un pays étranger. À la différence de la plupart des programmes de sensibilisation interculturelle qui se fixent essentiellement sur «le perçu» et sur les apports cognitifs offerts par la culture découverte (culture cible), le programme de «dépressurisation culturelle» analyse «le perceveur ", ou le comportement du sujet face à la culture étrangère Les sept "phases » de découverte vont de la perspective de la culture maternelle (contact avec l'altérité extrêmement limité) au "désengagement" (capacité à faire des choix responsables face à la double sollicitation des valeurs acquises dans l'environnement maternel et des alternatives proposées par une autre culture). En conclusion, nous proposons un appareil pédagogique, ou une série d'exercices de sensibilisation du groupe.

INDEX

Mots-clés: culture, interculturel, pédagogie interculturelle

Keywords: cross-cultural, cross-cultural pedagogy, culture

\section{AUTHOR}

\section{SUZETTE BRACE-LE BIGOT}

Suzette Brace-Le Bigot enseigne à l'IUT de l'Université de Paris 5. 